\title{
Comparison of the quantitative competitive and semiquantitative RT-PCR methods for the determination of interferon-gamma mRNA levels in AIDS-free HIV-infected individuals
}

É. Barabás, K. Nagy,

V. Várkonyi and $\mathrm{A}$. Horváth
National Institute of Dermato-Venereology, Budapest, Hungary

\section{Correspondence \\ É. Barabás \\ National Institute of \\ Dermato-Venereology \\ Mária utca. 41 \\ H-1085 Budapest \\ Hungary \\ Fax: + 36-1-267-6974 \\ E-mail: Bareva@bor.sote.hu}

Received November 27, 2000

Accepted July 25, 2001

\begin{abstract}
IFN- $\gamma$ mRNA expression was evaluated in nonstimulated peripheral blood mononuclear cells (PBMC) of HIV-infected and seronegative individuals using quantitative competitive and semiquantitative RTPCR and the sensitivity of these methods was compared. A significant correlation was found between quantitative competitive and semiquantitative RT-PCR in samples of both HIV-seronegative $(\mathrm{P}=0.004)$ and HIV-infected individuals $(\mathrm{P}=0.0004)$. PBMC from HIV-infected individuals presented a remarkable increase of IFN- $\gamma$ mRNA expression, as determined by both types of RT-PCR methods. Semiquantitative RT-PCR even without an internal standard is also acceptable for measuring cytokine mRNA expression, but less reliable if small amounts are quantified. Moreover, we found that increased IFN- $\gamma$ mRNA expression is independent of CD4+ cell count in AIDS-free HIV-infected patients.
\end{abstract}

\author{
Key words \\ - Q uantitative competitive \\ RT-PCR \\ - Semiquantitative RT-PCR \\ - IFN- $\gamma$ mRNA \\ - HIV
}

Cytokines are important regulators of immune responses. It has been suggested that a change in cytokine production occurs in HIV infection $(1,2)$. Most of these studies measured cytokine levels after stimulation of peripheral blood mononuclear cells (PBMC) in vitro due to the low concentration of cytokines under nonstimulated conditions (3). In contrast, determination of cytokine mRNA expression in nonstimulated PBMC would provide information about alterations in the cytokine network as a direct consequence of HIV (2-9).

IFN- $\gamma$ has an important role in the course of HIV infection (1-9), although its signifi- cance is not well understood. Both deficiency $(1,2)$ and overproduction (4-9) of IFN$\gamma$ have been reported in different studies.

Exact amounts of expressed cytokines can be quantified by means of highly sensitive methods. In the present study we determined IFN- $\gamma: \beta$-actin mRNA ratios by quantitative competitive reverse transcriptase polymerase chain reaction (QC RT-PCR) in nonstimulated PBMC from HIV-infected patients and healthy controls. The results were compared to those obtained by semiquantitative RT-PCR (SQ RT-PCR).

Twenty-five HIV-seropositive patients were selected at the HIV outpatient clinic of 
the National Institute of Dermato-Venereology, Budapest, Hungary. Six subjects with a CD4+ cell count $<200 / \mu 1$ (HIV $<200$ ), 12 patients with a CD4+ cell count $300-400 / \mu 1$ $(\mathrm{HIV}=300)$, and 7 subjects with a CD4+ cell count $>500 / \mu 1$ (HIV $>500)$ were included. Clinical examination showed no evidence of malignancies or rapid progression of the disease. None of them received antiretroviral therapy. Eleven HIV-seronegative healthy volunteers served as controls.

PBMC were separated from blood by Ficoll (Amersham Pharmacia Biotech, Uppsala, Sweden) density gradient centrifugation. Cells were suspended in cell membrane lysing solution (guanidine isothiocyanate- $\beta$ mercaptoethanol, Sigma, St. Louis, MO, USA). Total cellular RNA was purified (10). RT of RNA was performed according to the Perkin-Elmer protocol (Perkin-Elmer, Branchburg, NJ, USA). A thermocycler (PDR-91, BLS) was used for RT reaction (20 min at $42^{\circ} \mathrm{C}$, then $10 \mathrm{~min}$ at $99^{\circ} \mathrm{C}$ ). Two RT samples from each PBMC extract were used for RTPCR methods.

Semiquantitative reverse $R T-P C R$. cDNA equivalent to $500 \mathrm{ng}$ total RNA was amplified. PCR was performed in a final volume of $50 \mu \mathrm{l}$ containing $10 \mu \mathrm{l}$ R transcript, $2 \mu \mathrm{l}$ $\mathrm{MgCl}_{2}(25 \mathrm{mM}), 4 \mu \mathrm{l}$ 10-fold buffer II (500 $\mathrm{mM} \mathrm{KCl}, 100$ mM Tris-HCl, pH 8.3), 15 pM of each primer, and $0.25 \mu 1$ Taq polymerase (5 U/ $\mu$ l, Perkin-Elmer). The following primers were used: $\beta$-actin sense, 5' GTGGGG CGCCCCAGGCACCA 3'; antisense, 5' CTCCTTAATGTCACGCACGATTTC 3'; IFN- $\gamma$ sense, 5' AGTTATATCTTGGCTTT TCA 3'; antisense, 5' ACCGAATAATTA GTCAGCTT 3' (Promega, Madison, WI, USA). Samples were amplified using different cycle numbers: $\beta$-actin, 25 cycles (annealing at $65^{\circ} \mathrm{C}$ ) and IFN- $\gamma, 30$ cycles (annealing at $\left.52^{\circ} \mathrm{C}\right)$ each. PCR products $(18 \mu \mathrm{l})$ were electrophoresed on $2.5 \%$ agarose gel and visualized under ultraviolet light after ethidium bromide staining. Fragment sizes were $540 \mathrm{bp}$ for $\beta$-actin and $356 \mathrm{bp}$ for IFN- $\gamma$.
mRNA expression of $\beta$-actin and IFN- $\gamma$ was determined with a video-densitometry system (Eagleeye II, Amersham). Subsequently the IFN- $\gamma: ß$-actin ratio (mRNAs were detected in the same RT sample) in densitometric units was calculated in the analytical process $(2-4,6,8)$.

Quantitative competitive RT-PCR.cDNA equivalent to 400 ng total RNA was quantified by coamplification with nonhomologous internal standard fragments. Internal standard fragments for $\beta$-actin and IFN- $\gamma$ were prepared as previously described (11). A composite primer was used for the first reamplification step. 5' CTCCTTAATGTCA CGCACGATTTCCGTAGATGGGCACA GTGTGG 3' (annealing $60^{\circ} \mathrm{C}$ ) was used for B-actin and 5' ACCGAATAATTAGTCAGC TTGAGAACAATTTGGCTCTGC 3' (annealing $48^{\circ} \mathrm{C}$ ) (Promega) was used for IFN$\gamma$. Fragment size of the internal standards was $397 \mathrm{bp}$ for B-actin and 227 bp for IFN- $\gamma$. Concentrations of internal standard stock solutions were determined by absorbance measurement at $260 \mathrm{~nm}$. Molar concentrations $(\mathrm{mol} / \mathrm{l}=\mathrm{M})$ of stock solutions were $10^{-7} \mathrm{M}$ for $\beta$-actin and $10^{-8} \mathrm{M}$ for IFN- $\gamma$. Competitor stocks were diluted on a $0.5-\log$ scale. PCR was performed in a final volume of $50 \mu \mathrm{l}$ containing $8 \mu \mathrm{RT}$ transcript and 1 $\mu 1$ diluted internal standard. Thirty cycles were used for $\beta$-actin and 35 for IFN- $\gamma$. PCR products were amplified and detected as described in the previous section. The IFN- $\gamma$ : $\beta$-actin ratio (M/M) was used for the subsequent analysis.

Data were analyzed using the Statistica for Windows 5.1 software (12). Comparisons between groups were made by the MannWhitney U-test. Comparisons between QC RT-PCR and SQ RT-PCR results were performed by Pearson product-moment correlation and by Spearman rank correlation. Significance was defined as $\mathrm{P}<0.05$.

IFN- $\gamma$ mRNA expression determined by the IFN- $\gamma: \beta$-actin ratio showed a definite increase in both QC RT-PCR and SQ RT-PCR 
reactions. Quantitative competitive IFN- $\gamma$ : $\beta$-actin mRNA ratios $(\mathrm{M} / \mathrm{M})$ were significantly higher in all HIV-infected groups than in the HIV-seronegative group. There was no difference among HIV-positive groups with different CD4+ cell counts. Most IFN- $\gamma$ : $\beta$-actin mRNA ratios were below $10^{-4}(\mathrm{M} / \mathrm{M})$ among seronegative individuals, while they were above $10^{-4}(\mathrm{M} / \mathrm{M})$ among HIV-infected patients (Figure 1A).

Semiquantitative analysis showed significantly increased IFN- $\gamma: ß$-actin values in HIV $<200$ and HIV $>500$ patients compared to the seronegative group. The IFN- $\gamma: \beta$-actin ratio was higher in the HIV $=300$ group than in the control group, but this difference was not statistically significant. There was no difference in IFN- $\gamma: \beta$-actin values among the HIV-positive groups (Figure 1B).

A correlation between QC RT-PCR and SQ RT-PCR ratios could be found in both the HIV-negative (Figure 1C) and HIV-positive groups (Figure 1D).

Longitudinal study of six representative individuals showed that the QC RT-PCR IFN- $\gamma$ :ß-actin ratio was below $10^{-4}(\mathrm{M} / \mathrm{M})$ regarding HIV-negative individuals (Figure $2 \mathrm{~A}-\mathrm{C})$ and above $10^{-4}(\mathrm{M} / \mathrm{M})$ regarding HIVpositive patients (Figure 2D-F) at most time points. Variation of IFN- $\gamma$ levels was rather high in HIV-positive patients. QC RT-PCR and SQ RT-PCR showed a similar tendency in all longitudinal studies.

QC RT-PCR was shown to be more sensitive than SQ RT-PCR. Based on our findings, the QC RT-PCR system identified


Figure 1. Elevated interferon- $\gamma$ mRNA levels in AIDS-free HIV-infected individuals. A, IFN- $\gamma$ :ß-actin mRNA ratios (ratio of molar concentrations $=$ M/M) in HIV-seronegative (healthy controls, HC) and HIV-infected patients by quantitative competitive RT-PCR. B, IFN- $\gamma$ :ß-actin mRNA ratios (ratio in densitometric units = RDU) for HC and HIV-infected patients evaluated by semiquantitative RT-PCR. HIV-seropositive patients are divided into three groups based on CD4+ cell counts. The Mann-Whitney U-test was used for group comparisons. Significant differences between HIV-infected and HC groups are indicated. Correlation between quantitative competitive RT-PCR and semiquantitative RT-PCR IFN- $\gamma$ :ß-actin mRNA ratios for HC samples (C) and HIV-infected samples (D). Pearson product-moment $(*)$ and Spearman rank $(* *)$ correlations were used for the calculations (C,D). Each individual is indicated as a single point (A-D). 



Figure 2. Longitudinal study of the IFN- $\gamma$ :ß-actin mRNA ratio evaluated by quantitative competitive RT-PCR (ratio of molar concentrations = M/M) (lozenges) and semiquantitative RT-PCR (ratio of densitometric units = RDU) (squares): A-C, three HIV-seronegative individuals; D-F, three HIV-infected patients.

smaller differences between samples than the SQ RT-PCR method. Correlation analysis revealed weaker significance between QC RT-PCR and SQ RT-PCR results in healthy control than in HIV-positive samples, indicating that SQ RT-PCR was less reliable for smaller amounts of IFN- $\gamma$.

Correlation between results obtained by RT-PCR methods with different sensitivity showed that SQ RT-PCR, even without an internal standard, is also a reliable method for quantifying cytokine mRNA activity. Measuring a sample of large size is simple and fast. Using only SQ RT-PCR to measure cytokines, which are expressed at low levels, however, requires caution since the reliability of this method is lower when small amounts of mRNA are quantified.

Results of earlier studies on IFN- $\gamma$ expression measured by RT-PCR were controversial. Some studies reported a stronger
IFN- $\gamma$ expression in HIV-infected samples (4-9), others in HIV-negative samples $(1,2)$, and still others could not find any differences (3). We found significantly elevated IFN- $\gamma$ expression in AIDS-free HIV-positive patients by a less sensitive as well as a highly sensitive RT-PCR method. Independently of the duration of HIV infection and total CD4+ cell count, a marked increase of IFN- $\gamma$ mRNA expression could be observed by both methods.

Recently, it was reported that the major source of IFN- $\gamma$ in both HIV-seronegative and HIV-infected individuals is represented by CD8 + T cells $(7,9)$. Our results support the idea that permanent presentation of HIV1 antigens causes a strong CD8+ response in the asymptomatic phase, which also manifests as a permanent IFN- $\gamma$ activity. IFN- $\gamma$ has a role in the activation of some antiviral killing mechanisms. However, there are other 
deficiencies in the immune system which can counteract the effective antiviral activity. It may be suggested that IFN- $\gamma$ mRNA activity in the AIDS-free phase may be correlated with the activation of the immune system, which contributes to virus replication and spread in the human body (7).

\section{Acknowledgments}

We gratefully acknowledge the technical assistance of Gyöngyi Daróczi. We also thank Zsuzsa Faragó and Ágnes Végh for collection of blood samples, and Béla Kemény and József Bocsi for the flow cytometry analysis.

\section{References}

1. Clerici M \& Shearer M (1993). A Th1-Th2 switch is a critical step in the etiology of HIV infection. Immunology Today, 14: 107-111.

2. Diaz-Mitoma $F$, Kumar $A \&$ Karimi $S$ (1995). Expression of IL-10 and IL-4 and interferon-gamma in unstimulated and mitogen stimulated peripheral blood lymphocytes from HIV-seropositive patients. Clinical and Experimental Immunology, 102: 31-39.

3. Altfeld M, Addo MM, Kreutzer KA, Rockstroh J K, Dumoulin FL, Schliefer K, Leifeld L, Sauerbruch T \& Spengler U (2000). TH1 to $\mathrm{TH} 2$ shift of cytokines in peripheral blood of HIV-infected patients is detectable by reverse transcriptase polymerase chain reaction but not by enzyme-linked immunosorbent assay under nonstimulated conditions. J ournal of Acquired Immune Deficiency Syndromes, 23: 287294.
4. Fan J, Bass HZ \& Fahey JL (1993). Elevated IFN- $\gamma$ and decreased IL-2 gene expression are associated with HIV infection. J ournal of Immunology, 151: 50315040.

5. Graziosi $C$, Pantaleo $P$, Gantt KR, Fortin J P, Demarest J F, Cohen OJ , Sékaly RP \& Fauci AS (1994). Lack of evidence for the dichotomy of Th1 and Th2 predominance in HIV-infected individuals. Science, 265: 248-252.

6. McGown I, Radford-Smith G \& J ewell DP (1994). Cytokine gene expression in HIVinfected intestinal mucosa. AIDS, 8: 15691575.

7. Crabb-Breen E, Salazar-GonzalezJ F, Shen PL, Kolberg J A, Urdea MS, Martinez-Maza O \& Fahey J L (1997). Circulating CD8 T cells show increased interferon- $\gamma$ mRNA expression in HIV infection. Cellular Immunology, 178: 91-98.

8. Barabás É, Falus A, Nagy K, Várkonyi V,
Temesvári E \& Horváth A (1997). The dominant T-helper lymphocyte function of HIV infected patients. Pathology Oncology Research, 3: 67-73.

9. Empson M, Bishop GA, Nightingale B \& Garcia R (1999). Atopy, anergic status, and cytokine expression in HIV-infected subjects. J ournal of Allergy and Clinical Immunology, 103: 833-842.

10. Chomczynski $P \&$ Sacchi N (1987). Singlestep method of RNA isolation by acid guanidinium thiocyanate-phenol-chloroform extraction. Analytical Biochemistry, 162: 156-159.

11. Förster E (1994). An improved general method to generate internal standards for competitive PCR. BioTechniques, 16: 1820.

12. StatSoft, Inc. (1997). Statistica for Windows. Tulsa, OK, USA. 